\title{
Alemtuzumab Induced Thyroid Disease in Multiple Sclerosis: A Review and Approach to Management
}

\author{
Moeber Mahzari, Amel Arnaout, Mark S. Freedman
}

\begin{abstract}
Alemtuzumab, an anti-CD52 monoclonal antibody, was recently approved for treatment of MS in Canada, having shown to significantly reduce relapses and disability in patients, particularly those who relapsed despite first line treatment. Offsetting its benefit however, is the development of novel secondary autoimmune disease, particularly affecting the thyroid gland in up to $36 \%$ of patients. The incidence of Alemtuzumab induced thyroid dysfunction (AITD) will likely rise as alemtuzumab becomes more widely used for treating MS. We review the clinical and investigational cues that help delineate the aetiology and management of thyrotoxicosis and hypothyroidism in ATID. AITD can be easily managed and we present a simple approach for its evaluation and management by neurologists that should be implemented prior to considering a referral to an internist or endocrinologist for further opinion or treatment.
\end{abstract}

RÉSUMÉ: Maladie thyroïdienne induite par l'alemtuzumab dans la sclérose en plaques: revue et traitement. L'alemtuzumab, un anticorps monoclonal dirigé contre CD52, a récemment été approuvé pour le traitement de la sclérose en plaques (SP) au Canada. Les études ont démontré qu'il diminuait significativement les rechutes et l'invalidité chez les patients, particulièrement chez ceux qui avaient eu des rechutes malgré le traitement de première intention. Cependant, l'apparition d'une nouvelle maladie auto-immune secondaire à ce traitement, touchant la glande tyroïde chez $36 \%$ des patients, en amoindrit les bénéfices. L'incidence de la dysfonction thyroïdienne induite par l'alemtuzumab (DTIA) augmentera vraisemblablement à mesure que l'alemtuzumab sera plus fréquemment prescrit pour traiter la SP. Nous revoyons les indices cliniques et biochimiques qui aident à définir l'étiologie et le traitement de la thyrotoxicose et de l'hypothyrö̈die dans la DTIA. La DTIA peut être traitée facilement et nous présentons une approche simple de son évaluation et son traitement par des neurologues. Cette approche devrait être utilisée avant d'envisager de référer le patient à un interniste ou à un endocrinologue pour connaître son opinion ou pour prescrire un traitement.

Keywords: Alemtuzumab, multiple sclerosis, thyroid dysfunction

doi:10.1017/cjn.2015.48

Can J Neurol Sci. 2015; 42: 284-291

Multiple sclerosis (MS) is a debilitating chronic immunemediated disease of the central nervous system. ${ }^{1}$ The prevalence of autoimmune thyroid disease in the MS population in comparison to healthy people of comparable age and sex-distribution has been examined in several studies over the last decade with conflicting results; some suggest an increased prevalence whereas others report rates consistent with the prevalence in the general population. ${ }^{1-3}$

Alemtuzumab, a monoclonal antibody against CD52 recently approved for MS treatment in Canada, has been shown to significantly reduce MS relapse rate and risk of six month sustained accumulation of disability in patients who relapsed despite a first line treatment. Alemtuzumab also reduces relapses in naïve (untreated) patients with early active relapsing remitting multiple sclerosis. ${ }^{4,5}$ However, one significant side effect of Alemtuzumab is the development of novel secondary autoimmune disease. The thyroid gland is the most common target, being adversely affected in up to $36 \%$ of patients. Development of thyrotoxicosis after Alemtuzumab administration is the most common presentation. Thyroid disease developing in association with Alemtuzumab treatment appears to be different from the usual form of autoimmune thyroid conditions in that it tends to run a less aggressive course.
We report four cases of Alemtuzumab induced thyroid disease (AITD) to illustrate the clinical presentation and conservative management approach in this setting. We review the relevant literature and propose a management plan, including initial investigations and treatment that can be used by neurologists treating AITD.

\section{Case Descriptions}

Four out of seven patients enrolled in CARE-MS (Comparison of Alemtuzumab and Rebif Efficacy in Multiple Sclerosis) trials at a single centre developed AITD. The cases are described below and Table 1 summarizes patients' relevant history, physical findings, diagnostic tests and clinical course. One patient (patient 3) was

From the Division of Endocrinology and Metabolism (MM,AA); Division of Neurology (MSF), Department of Medicine, University of Ottawa; The Ottawa Hospital Research Institute(MSF), Ottawa, Ontario, Canada.

Received June 20, 2014. Final Revisions Submitted March 17, 2015. Correspondence to: Moeber Mahzari, University of Ottawa - Division of Endocrinology and Metabolism, Department of Medicine, 1967 Riverside Drive, Ottawa, ON K1H 7W9, Canada. E-mail: mmahzari@toh.on.ca 
Table 1: Case Descriptions

\begin{tabular}{|c|c|c|c|c|}
\hline & Patient 1 & Patient 2 & Patient 3 & Patient 4 \\
\hline Age(years)/gender & 49 /male & 37 /female & 34 /female & 34 /female \\
\hline $\begin{array}{l}\text { Time to diagnosis } \\
\text { from last } \\
\text { alemtuzumab dose }\end{array}$ & 12 months & 5 months & 16 months & 9 months \\
\hline Symptoms & $\begin{array}{l}\text { Weight loss, increased } \\
\text { defecation frequency, heat } \\
\text { intolerance }\end{array}$ & $\begin{array}{l}\text { Tremors, palpitations, sweating, } \\
\text { shortness of breath, weight loss }\end{array}$ & $\begin{array}{l}\text { Shortness of breath, palpitations } \\
\text { with minimal exertion, increased } \\
\text { appetite, weight loss, } \\
\text { menorrhagia }\end{array}$ & No symptoms \\
\hline $\begin{array}{l}\text { Significant findings } \\
\text { on physical } \\
\text { examination* }\end{array}$ & Thyroid was $2 \mathrm{x}$ normal size & Thyroid diffusely enlarged & $3.5 \mathrm{~cm}$ left thyroid lobe nodule** & $\begin{array}{l}\text { Smooth thyroid at the upper limits of } \\
\text { normal size }\end{array}$ \\
\hline $\begin{array}{l}\text { RAIU result } \\
\quad(\mathrm{N} \text { range } 6-22 \%)\end{array}$ & Increased uptake of $33 \%$ & Normal uptake of $9 \%$. & Increased uptake of $58.7 \%$ & Not done \\
\hline $\begin{array}{l}\text { Treatment } * * * \text { and } \\
\text { clinical course }\end{array}$ & $\begin{array}{l}\text { PTU for } 17 \text { weeks. } \\
\text { At week } 23 \text { after diagnosis } \\
\text { started on thyroid hormone } \\
\text { replacement for } \\
\text { hypothyroidism }\end{array}$ & $\begin{array}{l}\text { No anti-thyroid medication was } \\
\text { initiated } \\
\text { Twelve weeks after initial } \\
\text { presentation the patient was } \\
\text { started on thyroid hormone } \\
\text { replacement for hypothyroidism }\end{array}$ & $\begin{array}{l}\text { Methimazole for } 18 \text { months then } \\
\text { discontinued and patient } \\
\text { remained euthyroid }\end{array}$ & $\begin{array}{l}\text { No treatment at diagnosis } \\
\text { Thyroid function tests spontaneously } \\
\text { normalized over } 6 \text { months } \\
\text { A year later started on Levothyroxine } \\
\text { therapy for hypothyroidism }\end{array}$ \\
\hline
\end{tabular}

All patients had:

- Low TSH, high FT4 and high FT3 up on diagnosis.

- Negative TPO (thyroid peroxidise antibodies) prior alemtuzumab treatment.

Patient 1, 2, 3 had available and positive TPO antibodies up on diagnosis

*None of the patient had ophthalmopathy

**The patient underwent fine needle aspiration biopsy from the nodule that showed follicular neoplasm. Risk of malignancy in this type of cytology is around $20 \%$. The patient preferred US surveillance and surgery if the nodule increases in size.

***Beta-blockers used in the 3 symptomatic patients

$\mathrm{PTU}=$ propylthiouracil, $\mathrm{RAIU}=$ radioactive iodine uptake

diagnosed with Graves' disease (GD) while the three other patients had subacute painless thyroiditis (SPT). At our institution, the thyroid antibodies assay was changed during the time of CARE-MS trials. Three patients had anti-microsomal antibody measurement which is an agglutination immunoassay (reported as titre) while one patient (patient 3) had thyroid peroxidase level which is a quantitative chemiluminescent microparticle immunoassay.

\section{Patient 1}

A 49-year-old male with relapsing remitting MS received Alemtuzumab in March of 2009 and 2010 as part of the CAREMS II trial. We remain blinded to the dose (12 mg versus $24 \mathrm{mg}$ ) according to the study protocol. Alemtuzumab was given as an intravenous infusion for five days upon enrolment in the trial and for three days a year later. In March 2011 (one year after the second Alemtuzumab infusion), the patient started to notice symptoms of hyperthyroidism, including weight loss, increased defecation and heat intolerance. The patient does not have any family history of thyroid disease.

On examination, the thyroid was about two times the normal size, not tender and no bruit was noted. There were no findings of Graves' eye disease.

Thyroid uptake and scan was done around four weeks after the initial presentation and showed an increased uptake of $33 \%$ (normal range 6-22\%), which is compatible with GD. Anti-microsomal antibody was positive at 1:100 dilutions (it was negative upon enrolment in the trial). The patient was initiated on Propylthiouracil (PTU) $250 \mathrm{mg}$ twice daily at the time of diagnosis and was decreased to $250 \mathrm{mg}$ daily six weeks later upon normalization of free T4 and free T3. Seventeen weeks later the PTU was discontinued due to development of hypothyroidism and was initiated on Levothyroxine $100 \mathrm{mcg}$ per day at 23 weeks after initial presentation for persistent hypothyroidism. He continues to require thyroid hormone replacement over two years later.

\section{Patient 2}

A 37 year old female with relapsing remitting MS received Alemtuzumab as part of the CARE-MS I trial. She received intravenous Alemtuzumab $12 \mathrm{mg}$ per day for five days in January 2010. She subsequently received $12 \mathrm{mg}$ daily for three days a year later in accordance with the study protocol. Five months after the second infusion of Alemtuzumab, she began to note tremors, palpitations, sweating, occasional shortness of breath, and weight loss of $10 \mathrm{~kg}$ over two months.

On examination, the thyroid gland was diffusely enlarged (25 -30 g), firm, not tender with no palpable nodules and a faint bruit was present on the right lobe. There were no findings of Graves' eye disease.

Thyroid uptake and scan done around four weeks after the initial presentation of the patient, showed a radioactive iodine uptake of $9 \%$ (normal). Anti-microsomal antibody was positive at 1:400 dilutions (it was negative at enrolment in the trial).

The patient was prescribed propranolol for symptom management, but no anti-thyroid medication was initiated. Four weeks later, thyroid function tests were within normal. 
Twelve weeks after initial presentation the patient was initiated on Levothyroxine $100 \mathrm{mcg}$ per day for hypothyroidism. She continues to require thyroid hormone replacement 18 months later.

\section{Patient 3}

A 34-year-old female with relapsing remitting MS received Alemtuzumab in July of 2009 and 2010 as part of the CARE-MS II trial. We remain blinded to the dose given (12 $\mathrm{mg}$ versus $24 \mathrm{mg}$ ) according to the study protocol. Sixteen months after the second Alemtuzumab infusion, she noticed shortness of breath and palpitations with minimal exertion. Her appetite was increased but despite this, she lost 101 bs. She had menorrhagia but no ophthalmic symptoms. She has a family history of both hypothyroidism and hyperthyroidism.

On examination, she had a visible left thyroid lobe enlargement. There was a large palpable left thyroid mass. Her neck was not tender and there was no bruit. There was no finding of Graves' eye disease. Subsequent thyroid ultrasound confirmed a $3.5 \mathrm{~cm}$ left thyroid nodule.

Anti-TPO antibodies were elevated at 768KIU/L (normal level less than $6 \mathrm{KIU} / \mathrm{L}$ ), even though it was negative upon study enrolment. Thyroid uptake and scan showed an increased uptake of $58.7 \%$ consistent with GD. The dominant nodule in the left upper pole was "cold" (no uptake of tracer).

She was started on Methimazole $10 \mathrm{mg}$ twice daily along with a beta-blocker (Metoprolol) for a few weeks to control her symptoms. Thyroid function tests were better nine weeks after Methimazole initiation. The patient started to feel more fatigued than usual around twenty-two weeks after starting methimazole. She briefly discontinued this agent on her own but was re-started on it at $5 \mathrm{mg}$ per day two weeks later when the thyroid function tests showed a low thyroid stimulating hormome (TSH) suggestive of hyperthyroid state. Thyroid function tests 26 weeks later were normal; therefore the methimazole dose was reduced to $5 \mathrm{mg}$ every other day. Methimazole was discontinued completely around 20 months after onset of GD and she remains euthyroid for the past 12 months although her TSH fluctuates between being normal and mildly suppressed.

She underwent fine needle aspiration and biopsy of the left thyroid nodule, which showed a follicular neoplasm which is likely benign. The risk of differentiated thyroid cancer in this cytology result is $15-30 \%{ }^{6}$ It is therefore suggested that such patients undergo lobectomy for definitive diagnosis. ${ }^{7}$ Surveillance with thyroid ultrasound and thyroidectomy if the nodule shows progressive increase in size is an alternative option for patients who prefer a conservative approach. The patient opted to have ongoing surveillance with serial ultrasounds, which thus far showed stability in size and nodule characteristics.

\section{Patient 4}

A 34 year old female with relapsing remitting MS received Alemtuzumab as part of the CARE-MS I trial. She received intravenous Alemtuzumab $12 \mathrm{mg}$ per day for five days in January 2009. She subsequently received the same dose daily for three days a year later according to the study protocol. On routine blood work, nine months after the first dose of Alemtuzumab, she was found to have biochemical evidence of hyperthyroidism but was asymptomatic. She has no family history of thyroid disease.
On examination, the thyroid was found to be in the upper limits of normal size. There were no findings of Graves' eye disease

Anti-microsomal antibody was positive at 1:100 dilutions (it was negative upon enrolment).

Since the patient was asymptomatic; no treatment was initiated. Twelve weeks later free T4 and free T3 were normal with a low TSH. Follow up thyroid function tests 24 weeks later showed all thyroid indices were in the normal range.

A year after the initial presentation, the patient began to be more fatigued and developed a new symptom of constipation. Thyroid function tests showed hypothyroidism (elevated TSH, low free T4 and free T3) so she was initiated on Levothyroxine therapy.

\section{Discussion AND REVIEW}

Alemtuzumab is an approved treatment for MS in many countries and leads to autoimmune thyroid disease (AITD) in a third or more patients. Autoimmune thyroid disease could lead to either hypothyroidism or thyrotoxicosis and neurologists using this drug should be mindful of how to diagnose these conditions. Neurologists could easily initiate a work up and even start patients on treatment prior a referral to an endocrinologist.

A brief review of clinical and investigation clues that help in delineating the aetiology of AITD is presented below.

\section{Common Causes of thyrotoxicosis}

Although thyrotoxicosis and hyperthyroidism are commonly used interchangeably to designate the same disease process, there is a difference in meaning of the two terminologies. Thyrotoxicosis is a broad term denoting a state of increased thyroid hormone levels in the serum with a suppressed TSH regardless of the cause. Hyperthyroidism refers specifically to thyrotoxicosis resulting from increased thyroid hormone production as in aetiologies such as GD, toxic multinodular goitre and toxic thyroid adenoma. Grave's Disease constitutes an autoimmune disorder that increases thyroid hormone production due to TSH receptor stimulation by thyrotropin receptor antibodies (TRAbs). ${ }^{8}$ Subacute painless thyroiditis, on the other hand, is another important cause of thyrotoxicosis but results from release of preformed thyroid hormones secondary to autoimmune destruction of thyroid follicles without an increase in thyroid hormone synthesis. Both GD and SPT can present with the same symptoms but differentiating between the two causes of thyrotoxicosis is essential as the treatment differs. ${ }^{9}$ Subacute painless thyroiditis is typically a self-limiting disease while GD is not and will progress causing more severe disease unless treated with appropriate therapy.

\section{Differences between GD and SPT as a cause of thyrotoxicosis}

Differentiating GD from SPT can be obvious if the pattern of the thyrotoxicosis follows a predictable clinical course. ${ }^{9}$ Subacute painless thyroiditis causes an initial thyrotoxic phase secondary to the release of preformed thyroid hormones due to autoimmune thyroid destruction of thyroid follicles. Over weeks to months thyroid function recovers with the possibility of a hypothyroid phase during recovery. ${ }^{10}$ Over time, the chance of developing chronic thyroiditis and subsequent hypothyroidism is as high as $50 \%$ in all patients with SPT. ${ }^{11}$ On the other hand, GD is an 
Table 2: Symptoms and Signs

\begin{tabular}{l|l}
\hline Symptoms common to thyrotoxicosis due to all causes*: & Physical findings common to thyrotoxicosis due to all causes: \\
\hline - Anxiety & - Hyperactivity \\
- Weakness & Rapid speech \\
- Tremor & - Stare (lid retraction) and lid lag \\
- Emotional lability & - Warm and moist skin \\
- Heat intolerance & Thin hair \\
- Increased perspiration & - Tachycardia and cardiac tachyarrhythmias \\
- Weight loss despite a normal or increased appetite & - Systolic hypertension \\
- Hyperdefecation & Tremor \\
- Oligomenorrhea or amenorrhea in women & Proximal muscle weakness** \\
\hline Symptoms specific to thyrotoxicosis due to GD: & Pyperreflexia \\
\hline - Graves' ophthalmopathy symptoms including: & - Thyroid enlargement \\
o Dry and gritty ocular sensation, & Physical findings specific to thyrotoxicosis due to GD: \\
o Photophobia & Exophthalmos \\
o Excessive tearing & - Periorbital and conjunctivaledema \\
o Double vision & Limitation of eye movement \\
o Pressure sensation behind the eyes & Pretibial myxedema \\
o Upper eyelid retraction, & Thyroid enlargement with bruit \\
o Swelling and redness of the periorbital tissuesand conjunctivae & \\
o Eye protrusion &
\end{tabular}

*These symptoms are due to sympathetic overdrive secondary to increased thyroid hormone action in different tissues (Adapted from References 25,26,27) **Can be confused with those due to MS.

autoimmune process that rarely remits without treatment and in fact can become progressively worse over time. In general, the thyrotoxicosis caused by SPT is less severe than that observed with GD. However, the thyrotoxic symptoms are the same and it may be difficult to distinguish between the two diagnoses without the aid of specialized tests.

Various symptoms and signs are common to thyrotoxic states regardless of the etiology, but some are specific to GD (Table 2). The presence of Graves' ophthalmopathy is unique to GD and results from an autoimmune-mediated accumulation of hydrophilic glycosaminoglycans (GAG) in the extraocular muscles and retro-orbital connective and adipose tissue. ${ }^{12}$

The American Thyroid Association Practice Guidelines states that in a patient with a symmetrically enlarged thyroid, recent onset of ophthalmopathy, and persistent, high levels of thyroid hormone for weeks to months, the diagnosis of GD is sufficiently likely that further evaluation of hyperthyroidism causation is unnecessary. ${ }^{9}$

The absence of classical GD physical findings in the setting of thyrotoxicosis necessitates further investigations to distinguish between GD and SPT and to further guide treatment. A radioactive iodine uptake (RAIU) test should be performed (except during pregnancy when it is contraindicated). Radioactive iodine uptake, a measure of thyroid hormone synthesis, will be elevated and occasionally normal in cases of GD but extremely low in cases of SPT. ${ }^{9}$ However, normal or even elevated RAIU has been reported in patients with SPT if RAIU is carried out during the recovery phase of SPT. ${ }^{13,14}$ Therefore, the earlier the RAIU is carried out at the time of diagnosis of thyrotoxicosis, the more accurate the interpretation. That is why initiating this test before a referral to endocrinology is important.
An alternative way to distinguish between GD and SPT is to measure specific thyroid antibodies. ${ }^{8,15,16}$ Thyroid receptor antibodies, otherwise known as thyroid binding immunoglobulins (TBII), have a specificity of $99 \%$ and sensitivity of $97 \%$ for diagnosing GD. ${ }^{13}$ Thyroid Peroxidase antibodies (anti-TPO) are almost always positive in SPT and up to $70 \%$ of GD; therefore they are not useful to make a distinction between the two conditions. $^{8,15}$

\section{Hypothyroidism}

Symptoms and signs for hypothyroidism are less specific and overlap with those of many other medical conditions, including MS. Common symptoms of hypothyroidism include, dry skin, cold sensitivity, fatigue, muscle cramps, voice change, and constipation. Severe hypothyroidism can also present with carpal tunnel syndrome and sleep apnea. Periorbital edema, delayed relaxation of muscle stretch reflexes, and bradycardia are some physical signs associated with hypothyroidism.

A diagnosis of primary hypothyroidism in a patient with MS can be overlooked due to the non-specific symptoms that mimic those of MS. There should be a low threshold to investigate these patients by obtaining a TSH level. An elevated TSH above the reference range in a patient with new symptoms compatible with hypothyroidism is enough to confirm the diagnosis of hypothyroidism. Permanent hypothyroidism associated with Alemtuzumab treatment can occur due to progressive autoimmune destruction of thyroid tissue. However, a transient hypothyroidism can occur during the recovery phase of SPT. The diagnosis of hypothyroidism is unlikely to be missed in Alemtuzumab treated patients since screening for thyroid dysfunction in 
this population is recommended on a regular basis as part of their clinical and laboratory surveillance program.

\section{The incidence of AITD}

Alemtuzumab use in MS patients causes hypothyroidism and thyrotoxicosis. The latter comprises mostly SPT and GD. The incidence of AITD reported in clinical trials is briefly summarized below.

In a recent four year follow up analysis of patients in CARE MS I and II trials, the overall incidence of thyroid adverse events was $\sim 36 \%$. Reported thyroid adverse events in the CARE MS trials included hypothyroidism, hyperthyroidism/GD, goitre, thyroiditis, thyroid disorder, thyroid mass, thyrotoxic crisis, abnormal laboratory investigations, endocrine ophthalmopathy and thyroidectomy. ${ }^{17}$ The definition of each adverse event is not available. Therefore, it is important to emphasize that there is probable overlap between the terminologies used to report thyroid adverse events. For instance thyroiditis could present with thyrotoxicosis (which commonly referred to as hyperthyroidism) early in its course and hypothyroidism later on. Thyroid goitre and thyroid mass are anatomic descriptions of aberrant thyroid anatomy. Patients with a thyroid goitre could be hyperthyroid (as in GD), hypothyroid (as in Hashimoto thyroiditis) or euthyroid. "Abnormal blood work" and "thyroid disorder" are very vague terms and could mean hypothyroidism or hyperthyroidism. Finally thyroidectomy is an intervention for an underlying thyroid disorder rather than a thyroid adverse event.
The most commonly reported thyroid adverse events in the CARE MS trials are hypothyroidism, hyperthyroidism/GD and SPT. Overall the majority of thyroid adverse events occurred within the first three years following the first Alemtuzumab infusion with the incidence peaking at year three. This similar pattern of appearance of thyroid disease was seen previously in the CAMMS223 phase II trial. ${ }^{17,18}$ The yearly incidence of hypothyroidism ranged from 5.7-20.9\%, whereas that of all causes of thyrotoxicosis, including GD, ranged from $1.2-11.9 \%$; the yearly incidence of SPT ranged between $0.7-1.9 \%$. A summary of incidence of thyroid adverse events in CARE MS trials is presented in Table 3 . $^{17}$

Two patients in CARE MS I and one patient in CARE MS II are reported to have papillary thyroid cancer diagnosed during the trial. In CARE MS I, one patient had a thyroid nodule on study entry and the second patient was found to have a suspicious thyroid nodule by thyroid ultrasound while on treatment for thyrotoxicosis. The patient subsequently underwent hemithyroidectomy followed by radioactive iodine treatment. Thyroid nodules are common in the general population with a prevalence of around $60 \%$ based on thyroid ultrasound studies. ${ }^{7}$ Only five percent of all thyroid nodules turn out to be biopsy-proven thyroid cancer. Rotie et al reported that $4.1 \%$ of patients who underwent thyroidectomies for GD or multinodular goitre were incidentally found to have micropapillary thyroid cancer ${ }^{19}$ In a large autopsy study from multiple countries, the incidence of occult papillary thyroid cancer was 5.6-28 \%. ${ }^{20}$ Further studies are required to assess the causal relationship between thyroid cancer and Alemtuzumab treatment.

Table 3: Reported thyroid adverse events in CARE MS Trials

\begin{tabular}{|c|c|c|c|c|c|}
\hline \multirow{3}{*}{ Adverse Events } & \multicolumn{4}{|c|}{ Alemtuzumab dose } & \multirow{3}{*}{$\begin{array}{c}24 \mathrm{mg}^{* *} \\
\text { Total }(\mathrm{n}=161)\end{array}$} \\
\hline & \multicolumn{4}{|c|}{$12 \mathrm{mg}$} & \\
\hline & Year1 $(n=811)$ & Year2 $(n=810)$ & Year3 $(n=772)$ & Year4 $(n=731)$ & \\
\hline Hypothyroidism & $1.7 \%$ & $2.7 \%$ & $4.9 \%$ & $2.7 \%$ & Thyroid AEs were reported in $37.3 \%$ \\
\hline Hyperthyroidism & $1.2 \%$ & $4.1 \%$ & $11.9 \%$ & $6.0 \%$ & \\
\hline Thyroiditis & $0.7 \%$ & $1.5 \%$ & $1.9 \%$ & $1.4 \%$ & \\
\hline Goitre & $0.6 \%$ & $0.9 \%$ & $0.9 \%$ & $1.0 \%$ & \\
\hline Thyroid disorder & $0 \%$ & $0 \%$ & $0.3 \%$ & $0 \%$ & \\
\hline Thyroid mass & $0 \%$ & $0.1 \%$ & $0 \%$ & $0 \%$ & \\
\hline Thyrotoxic crisis & $0 \%$ & $0.1 \%$ & $0 \%$ & $0 \%$ & \\
\hline Abnormal laboratory investigations & $2.0 \%$ & $2.7 \%$ & $4.1 \%$ & $2.3 \%$ & \\
\hline Thyroidectomy & $0 \%$ & $0.1 \%$ & $0.6 \%$ & $1.8 \%$ & \\
\hline \multicolumn{6}{|l|}{ Serious thyroid Adverse events* } \\
\hline Hypothyroidism & $0 \%$ & $0.2 \%$ & $0.1 \%$ & $0 \%$ & Incidence of thyroid Serious AEs was 3.7\% \\
\hline Hyperthyroidism & $0.1 \%$ & $0.4 \%$ & $2.7 \%$ & $0.4 \%$ & \\
\hline Goitre & $0.1 \%$ & $0 \%$ & $0.1 \%$ & $0 \%$ & \\
\hline Thyrotoxic crisis & $0 \%$ & $0.1 \%$ & $0 \%$ & $0 \%$ & \\
\hline Endocrine ophthalmopathy & $0 \%$ & $0 \%$ & $0.1 \%$ & $0.1 \%$ & \\
\hline Abnormal laboratory investigations & $0 \%$ & $0.1 \%$ & $0 \%$ & $0 \%$ & \\
\hline
\end{tabular}

*Serious adverse events represent grade 4 or above based on national cancer institute common terminology criteria of adverse events version 3.0.

**No details available

$\mathrm{AE}=$ adverse events 
Table 4: Reported thyroid adverse events in CAMMS223*

\begin{tabular}{l|c|c}
\hline Adverse Events & 12 mg (n= 108) & Alemtuzumab dose \\
\hline Overt hyperthyroidism due to GD & $19.4 \%$ & $1.9 \%$ \\
\hline Overt hyperthyroidism due to subacute thyroiditis & $5.6 \%$ & $16.7 \%$ \\
\hline Subclinical hyperthyroidism due to GD & $1.9 \%$ & $2.7 \%$ \\
\hline Subclincal hyperthyroidism due to subacute thyroiditis & $7.4 \%$ & $0.9 \%$ \\
\hline Overt hypothyroidism & $1.9 \%$ & $3.7 \%$ \\
\hline Subclinical hyperthyroidism & $0.9 \%$ & \\
\hline
\end{tabular}

Median of 57.3 months of follow-up

$\mathrm{GD}=$ Grave's disease

Daniels et $\mathrm{al}^{18}$ did an extensive review of all thyroid dysfunction that occurred in the phase II study of Alemtuzumab in MS (CAMMS223). Thyroid adverse events were defined clearly and included overt and subclinical hyperthyroidism and overt and subclinical hypothyroidism. Hypothyroidism occurred in $6.9 \%$ of patients. Overall $23 \%$ of patients who received Alemtuzumab developed GD, which was diagnosed if thyrotoxicosis persisted for more than three consecutive months or if TBIIs were positive during the three months before or after the low TSH was noted. Subacute painless thyroiditis was reported in $4.2 \%$ of patients, diagnosed when thyrotoxicosis was followed by spontaneous euthyroidism or hypothyroidism and TBIIs were negative. In addition, 30\% of patients with AITD experienced more than one episode of GD, hypothyroidism or SPT over time (same or different). Interestingly, spontaneous resolution of overt GD occurred in $36 \%$ of patients and some went on to develop spontaneous hypothyroidism. ${ }^{18} \mathrm{~A}$ summary of incidence of thyroid adverse events in CAMMS223 trial is presented in Table 4.

Cossburn et al. ${ }^{21}$ reported higher thyroid autoimmune adverse event rate of $77.36 \%$ of 248 patients who received Alemtuzumab (a median cumulative dose of $96 \mathrm{mg}$ over one to four courses). GD accounted for $70.73 \%$ and transient thyroiditis for $12.2 \%$ of all thyroid adverse events, with the remainder developing hypothyroidism.

\section{Management of SPT versus GD in general}

Beta-adrenergic blockers can be used to treat thyrotoxic symptoms regardless of the cause. In SPT, anti-thyroid drugs that block thyroid hormone production in the thyroid follicular cells are not needed since new hormone synthesis is already low in these patients. Rarely, corticosteroids have been used to ameliorate the severity and to shorten the course of thyrotoxicosis due to SPT, but they should be reserved only for severe cases. ${ }^{9}$ It is possible that some patients will have recurrent episodes of SPT, separated by years, ${ }^{10}$ requiring a similar treatment strategy.

Grave's disease should be managed by any of the following modalities: anti-thyroid medication, ${ }^{131} \mathrm{I}$ therapy or thyroidectomy. The treatment choice is based on patient preference and recommendation from a qualified internist or endocrinologist. Medical treatment is generally suggested in patients with mild disease, with small goitres and low TRAb titres, since these patients tend to have good rates of disease remission. Hence there is often no need to expose patients to the surgical risks involved with thyroidectomy or the need for long term thyroid hormone replacement therapy expected with ${ }^{131}$ I therapy. ${ }^{8}$

\section{Treatment of Alemtuzumab induced thyrotoxicosis in major trials}

There is a suggestion that the course of thyrotoxicosis in GD caused by AITD is less severe than conventional GD since the majority of patients with Alemtuzumab induced GD were managed successfully with medical treatment alone, or went into remission spontaneously. ${ }^{22}$

Medical therapy of conventional GD with thionamides is almost always effective initially but relapse of GD is reported in up to $42 \%$ of patients treated with thionamides alone. ${ }^{23}$ In contrast, Crossbun et al. reported that only $28 \%$ of patients with AITD GD required radioactive iodine (RAI) due to failure of medical treatment. ${ }^{21}$ In the CAMMS223 trial, $36.7 \%$ of those with overt GD due to AITD resolved spontaneously while the rest received therapy $(40.1 \%$ anti-thyroid drugs alone, $12.2 \%$ anti-thyroid drugs and RAI, $6.1 \%$ RAI alone, and $4 \%$ surgery). In other words, $76.8 \%$ of the patients with GD due to AITD in CAMMS223 did not require RAI or thyroidectomy. ${ }^{18,22}$ It is not described in detail when RAI or thyroidectomies were done, or whether it was due to failure of medical treatment or physician and patient preference.

In the CARE-MS trials thyroidectomy was conducted in 22 patients to treat thyroid adverse events, and it is unclear if any of the thyroidectomies were done for GD. The rest of the patients were treated conventionally; the details of conventional therapy are not available. $^{17}$

The suggestion that Alemtuzumab induced GD is less aggressive compared to conventional GD will need to be confirmed in longer term follow up.

\section{Management approach to Alemtuzumab induced thyroid dysfunction}

\section{Treatment of Alemtuzumab induced hypothyroidism}

Any patient with a TSH level of $>10 \mathrm{mIU} / \mathrm{L}$ should be considered for thyroid hormone replacement therapy regardless of symptoms. Patients with TSH levels between the upper limit of a given laboratory's reference range and $10 \mathrm{mIU} / \mathrm{L}$ should be considered for thyroid hormone replacement if they have symptoms consistent with recent onset hypothyroidism. For patients started on thyroid hormone therapy TSH should be monitored 


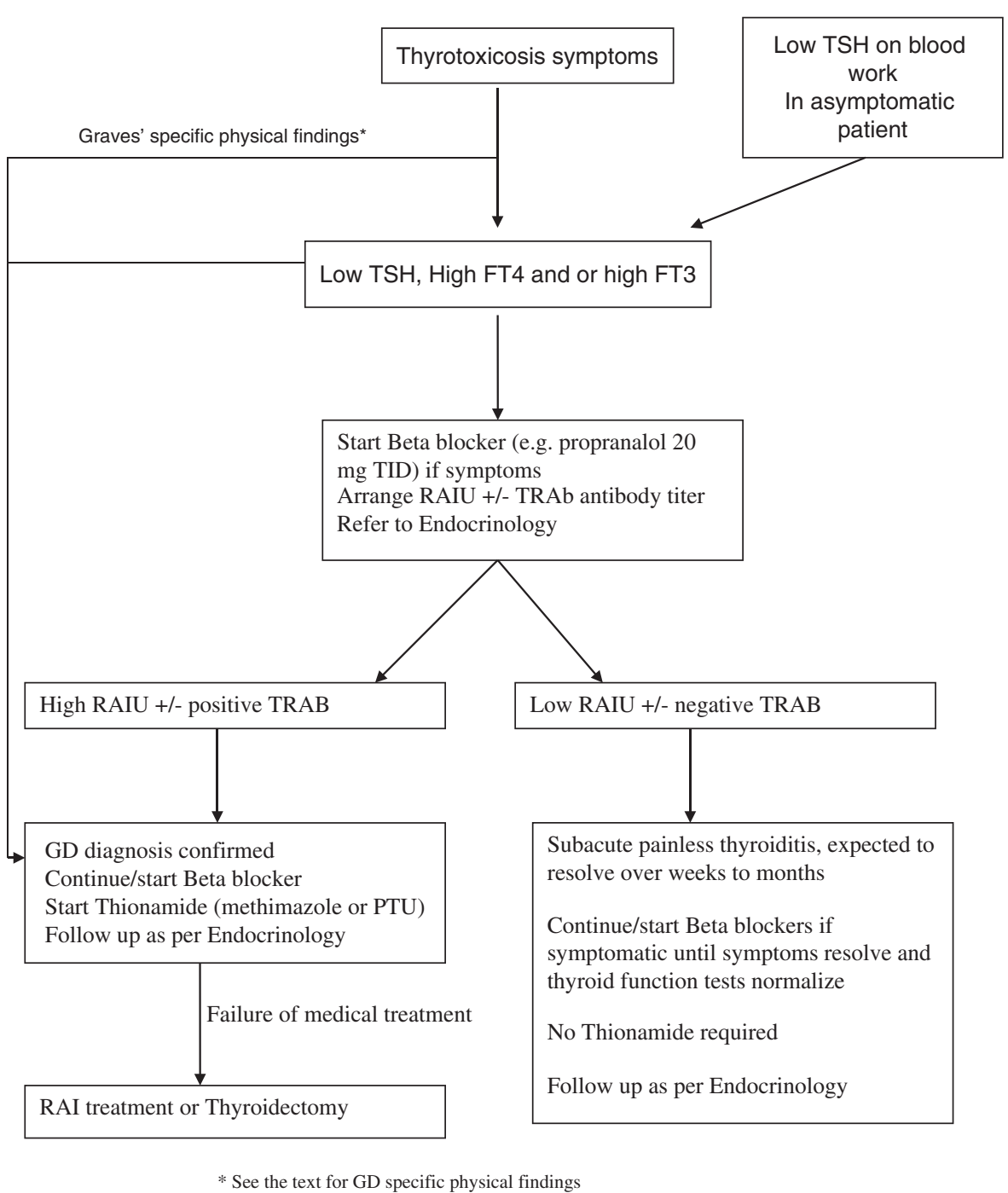

Figure 1: A suggested evaluation and initial treatment approach for patients with Alemtuzumab induced thyrotoxicosis.

every four to eight weeks initially to adjust thyroid hormone replacement dose targeting normal TSH level. ${ }^{24}$ If hypothyroidism develops after thyrotoxicosis, then SPT should be suspected but hypothyroidism may be transient, therefore reassessment of ongoing need for thyroid hormone replacement is recommended.

\section{Treatment of Alemtuzumab induced thyrotoxicosis}

Thyrotoxicosis after Alemtuzumab treatment is more likely to be due to GD, although a significant number of patients could present in the thyrotoxicosis phase of SPT. Even patients with GD due to AITD appear to have a more favourable course compared to patients with conventional GD. Majority of patients with AITD related GD in Alemtuzumab clinical trials was managed with medical treatment and demonstrated a higher likelihood of remission. Therefore, we suggest a conservative approach in these patients. RAI and thyroidectomy are indicated in cases with documented failure of medical treatment. Figure 1 outlines a suggested evaluation and initial treatment approach that could be initiated until the patient is sent to an internist or endocrinologist.

\section{Conclusion}

The incidence of AITD will likely rise as Alemtuzumab becomes more widely used for treating MS. Thyroid function testing is recommended to be done every three months after Alemtuzumab treatment for four years after initiating treatment and for four years after the last infusion, therefore it is unlikely to miss AITD in these patients. Alemtuzumab induced thyroid disease is a significant adverse effect of the medication but is relatively easy to manage. We suggest a simple approach that could be undertaken by physicians treating MS patients. This approach will serve to differentiate the underlying aetiology of the thyroid dysfunction and initiate a treatment plan until the patient can be seen by an endocrinologist or an internist. It is also important to note that spontaneous remission of overt thyrotoxicosis occurs in a significant proportion of patients which allows for a conservative approach to management. Alemtuzumab induced thyroid disease, arising with this important new therapy for MS, should not deter physicians from considering its use. 


\section{DisCLOSURES}

Moeber Mahzari has nothing to disclose. Amel Arnaout has nothing to disclose. Mark Freedman has the following disclosures: Genzyme, Consultant Advisor, Consulting fee/honoraria, Biogen Idec, Consultant Advisor, Consulting fee/honoraria, EMD Canada, Consultant Advisor, Consulting fee/honoraria, Teva Canada, Consultant Advisor, Consulting fee/honoraria, Novartis, Consultant Advisor, Consulting fee/honoraria

Sanofi, Consultant Advisor, Consulting fee/honoraria, Opexa, Consultant Advisor, Consulting fee/honoraria, Chugal, Adjudication Committee, Consulting fee/honoraria

\section{REFERENCES}

1. Marrie A, Yu BN, Leung S, et al. The incidence and prevalence of thyroid disease do not differ in the multiple sclerosis and general populations: A validation study using administrative data. Neuroepidemiology. 2012;39:135-42.

2. Sloka JS, Phillips PW, Stefanelli M, Joyce C. Co-occurrence of autoimmune thyroid disease in a multiple sclerosis cohort. J Autoimmune Dis. 2005;2:9.

3. Niederwieser G, Buchinger W, Bonelli RM, et al. Prevalence of autoimmune thyroiditis and non-immune thyroid disease in multiple sclerosis. J Neurol. 2003;250:672-5.

4. Coles AJ, Twyman CL, Arnold DL, et al. Alemtuzumab for patients with relapsing multiple sclerosis after disease-modifying therapy: A randomised controlled phase 3 trial. Lancet. 2012;380: 1829-39.

5. Cohen JA, Coles AJ, Arnold DL, et al. Alemtuzumab versus interferon beta $1 \mathrm{a}$ as first-line treatment for patients with relapsingremitting multiple sclerosis: A randomised controlled phase 3 trial. Lancet. 2012;380:1819-28.

6. Cibas ES, Ali SZ, and the NCI Thyroid FNA State of the Science Conference. The Bethesda system for reporting thyroid cytopathology. Am J Clin Pathol. 2009;132:658-65.

7. American Thyroid Association (ATA) Guidelines Taskforce on Thyroid Nodules and Differentiated Thyroid Cancer, Cooper DS, Doherty GM, Haugen BR, et al. Revised American Thyroid Association management guidelines for patients with thyroid nodules and differentiated thyroid cancer. Thyroid. 2009;19:1167-214.

8. Mariotti S, Caturegli P, Piccolo P, Barbesino G, Pinchera A. Antithyroid peroxidase autoantibodies in thyroid diseases. J Clin Endocrin Metabol. 1990;71:661-9.

9. Bahn RS, Burch HB, Cooper DS, et al. Hyperthyroidism and other causes of thyrotoxicosis: Management guidelines of the American Thyroid Association and American Association of Clinical Endocrinologists. Endocr Prac. 2011;17:456-520.

10. Nikolai TF, Coombs GJ, McKenzie AK. Lymphocytic thyroiditis with spontaneously resolving hyperthyroidism and subacute thyroiditis. long-term follow-up. Arch Int Med. 1981;41:1455-8.
11. Samuels MH. Subacute, silent, and postpartum thyroiditis. Med Clin North Am. 2012;96:223-33.

12. Burch HB, Wartofsky L. Graves' ophthalmopathy: Current concepts regarding pathogenesis and management. Endocrine Rev. 1993; 14:747-93.

13. Nabhan ZM, Kreher NC, Eugster EA. Hashitoxicosis in children: Clinical features and natural history. J Pediatr. 2005;146:533-6.

14. Ramtoola S, Maisey MN, Clarke SE, Fogelman I. The thyroid scan in hashimoto's thyroiditis: The great mimic. Nucl Med Commun. 1988;9:639-45.

15. Tozzoli R, Bagnasco M, Giavarina D, Bizzaro N. TSH receptor autoantibody immunoassay in patients with graves' disease: Improvement of diagnostic accuracy over different generations of methods. systematic review and meta-analysis. Autoimmun Rev. 2012;12:107-13.

16. Barbesino G, Tomer Y. Clinical review: Clinical utility of TSH receptor antibodies. J Clin Endocrinol Metabol. 2013;98:2247-55.

17. Twyman C, Oyuela P, Palmer J, Margolin D, Dayan C. Thyroid autoimmune adverse events in patients treated with alemtuzumab for relapsing-remitting multiple sclerosis: Four-year follow-up of the CARE-MS studies (P2.199). Neurology. 2014;82(10 Supplement): P2. 199.

18. Daniels GH, Vladic A, Brinar V, et al. Alemtuzumab-related thyroid dysfunction in a phase 2 trial of patients with relapsing-remitting multiple sclerosis. J Clin Endocrinol Metabol. 2014;99:80-9.

19. Roti E, Rossi R, Trasforini G, et al. Clinical and histological characteristics of papillary thyroid microcarcinoma: Results of a retrospective study in 243 patients. J Clin Endocrinol Metabol. 2006;91:2171-8.

20. Fukunaga FH, Yatani R. Geographic pathology of occult thyroid carcinomas. Cancer. 1975;36:1095-9.

21. Cossburn M, Pace AA, Jones J, et al. Autoimmune disease after alemtuzumab treatment for multiple sclerosis in a multicenter cohort. Neurology. 2011;77:573-9.

22. Weetman AP. Graves' disease following immune reconstitution or immunomodulatory treatment: Should we manage it any differently? Clin Endocrinol. 2014;80:629-32.

23. Torring O, Tallstedt L, Wallin G, et al. Graves' hyperthyroidism: Treatment with antithyroid drugs, surgery, or radioiodine-a prospective, randomized study. thyroid study group. J Clin Endocrinol Metabol. 1996;81:2986-93.

24. Garber JR, Cobin RH, Gharib H, et al. Clinical practice guidelines for hypothyroidism in adults: Cosponsored by the American Association of Clinical Endocrinologists and the American Thyroid Association. Endocr Prac. 2012;18:988-1028.

25. Trzepacz PT, Klein I, Roberts M, Greenhouse J, Levey GS. Graves' disease: An analysis of thyroid hormone levels and hyperthyroid signs and symptoms. Am J Med. 1989;87:558-61.

26. Woeber KA. Thyrotoxicosis and the heart. New Engl J Med. 1992;327:94-8.

27. Bahn RS. Graves' ophthalmopathy. New Engl J Med. 2010;362: 726-738. 